\title{
Age Related Cognitive Impairment and Physical Disability to Measure Quality of Life (QoL) Using PSCQL-MT Tool in the Senior Citizens of Lahore, Pakistan
}

\author{
Hamid Mahmood ${ }^{1, ~ *, ~ A m m a r a ~ W a q a r ², ~ M u h a m m a d ~ Y a q o o b ~}{ }^{1}$, Ejaz Mahmood Ahmad Qureshi', \\ Saleem Rana ${ }^{1}$, Syed Amir Gilani ${ }^{1}$, Asif Hanif ${ }^{1}$, Awais Gohar ${ }^{3}$ \\ ${ }^{1}$ University Institute of Public Health, The University of Lahore, Lahore, Pakistan \\ ${ }^{2}$ Quality Enhancement Cell, Al-Aleem Medical College, Lahore, Pakistan \\ ${ }^{3}$ Primary and Secondary Health Department, Government of the Punjab, Lahore, Pakistan
}

\section{Email address:}

drhamidmahmood373@gmail.com (H. Mahmood), ammarahamid24@gmail.com (A. Waqar), yaqoobchich@yahoo.com (M. Yaqoob), ejaz_qureshi@hotmail.com (E. M. A. Qureshi), saleem.uiph@gmail.com (S. Rana),profgilani@gmail.com (S. A. Gilani), asif.hanif@ahs.uol.edu.pk (A. Hanif), dr.awais.gohar@gmail.com (A. Gohar)

${ }^{*}$ Corresponding author

\section{To cite this article:}

Hamid Mahmood, Ammara Waqar, Muhammad Yaqoob, Ejaz Mahmood Ahmad Qureshi, Saleem Rana, Syed Amir Gilani, Asif Hanif, Awais Gohar. Age Related Cognitive impairment and Physical Disability to Measure Quality of Life (QoL) Using PSCQL-MT Tool in the Senior Citizens of Lahore, Pakistan. American Journal of Biomedical and Life Sciences. Vol. 8, No. 5, 2020, pp. 173-184. doi: $10.11648 /$ j.ajbls.20200805.16

Received: August 15, 2020; Accepted: August 26, 2020; Published: September 16, 2020

\begin{abstract}
The impact of physical exercise activity and cognitive executive functions and their impact on the QoL is of great importance in performing ADL and IADL in the senior citizens. This study will provide an inside into multidimensional factors which can impact the cognitive and physical mobility of the persons in the old age. Moreover, it is also desirable to measure the QoL on the basis of PSCQL-MT on a larger scale for longer duration of time. The role of gender on the QoL using different variables needs to be further evaluated. The objectives of the study are: To find out the relationship between the cognitive improvement due to physical exercise activities in the elderly persons. To find out the effect of different variables on QoL in male and female. The following hypothesis will be tested based on PSCQL-MT questionnaire. H1: Physical exercise activities play an important role in stabilizing or improving the cognitive functions on the basis of gender in the study population. $\mathrm{H} 2$ : Physical exercise activities do not play an important role in stabilizing or improving the cognitive functions on the basis of gender in the study population. The result of the study showed that recent physical exercise activity does not play any significant role in improving the QoL. The cognitive functions in the senior citizens who perform ADL and IADL depend upon the physical mobility and mental ability for the persons. The long term physical exercise activity, socio-cultural level, lifestyle, leisure activities and health behavior play a significant in maintaining the cognitive functions and physical health in the senior citizens. The scope of this study was to find out the moderating factors which can preserve cognitive executive functions in the senior citizens. Our study is more related on the concept of physical exercise activities and its impact on the cognitive executive functions in the elderly. The PSCQL-MT questionnaire contains all the dimensions which are necessary to find out the relationship of physical activities and cognitive functions in terms of ADL and IADL. The PSCQL-MT questionnaire and the modified questionnaires are very closed in terms of their dimensions. We concluded from the study that physical exercise activity in the long term is very important in preserving the cognitive functions in the elderly persons. We also found out that the PSCQL-MT questionnaire is a good addition to conduct research on the different aspects of healthy living in the different population.
\end{abstract}

Keywords: Physical Exercise Activity, Cognitive Functions, PSCQL-MT, Measurement Tool, Quality of Life (QoL), Senior Citizen 


\section{Introduction}

The study "Physical Exercise Activity, Cognitive Functions and Its Relationship to Quality of Life in the Senior Citizens of Lahore" has been carried out previously to find out the impact of physical exercise activity and cognitive executive functions. In the study "Development, Testing of Construct Validity and Reliability of Pakistan Senior Citizens Quality of Life - Measurement Tool (PSCQL-MT) to Measure QoL in Senior Citizens of Lahore, Pakistan" the validation liability and construct validly of (PSCQL-MT) was tested and retested on limited scale. The results of both studies have provided us evidence the correlation with physical exercise activity and cognitive executive functions to measure the quality of life in the study population.

This study will be carried out on a larger scale in the subject population to testify our hypothesis.

From the previous 2 studies it has been found out that the recent physical activity does not show any significant improvement in preserving cognitive functions regardless of gender. It has been found out that the long term physical exercise activity seems to provide benefit in preservation of cognitive executive functions which improve to perform $\mathrm{ADL}$ and IADL. Now the question rises about the existence of other behavior which can save the senior citizens from physical and cognitive decline in the aging population. Hence, this study will provide an inside into multidimensional factors which can impact the cognitive and physical mobility of the persons in the old age. Moreover, it is also desirable to measure the QoL on the basis of PSCQL-MT on a larger scale for longer duration of time. The role of gender on the QoL using different variables needs to be further evaluated.

This study is about the benefits of the intervention program which has been spread over months to find out the impact of physical exercise activities and cognitive improvement in the senior citizens. This study will provide us the theme which will specifically be focused on physical activity, cognitive executive functions, social interactions and new leisure activities that can affect the QoL in the senior citizens. To answer these questions, a theoretical framework has been chosen which can directly or indirectly can affect the cognitive functions in the elderly persons. This study will also provide us the difference in physical activities exercises and cognitive functions on the basis of gender differences.

\section{Background}

This study has been carried out on the physical activities and its relation to cognitive executive functions about the maintenance of ADL and IADL. The cognitive functions are the executive functions which are important with reference activities of daily life and occupational health to perform its job. The physical activities are important to maintain wellbeing for him. Both these factors are important to continue social interaction, leisure activities and all other activities which further improve the QoL.

Our study is focused on the primary factors which affect the QoL that is cognitive executive function and physical activity. The cognitive function measurement is early started on the basis of Cattell's model which shows that the cognitive functions begins to decline in the earlier adulthood.

The concept of "aging well" is the focus on maintaining global health. The process of aging starts since the time of conception in mother's womb and continue till death. Audiffren et al. carried out a research to find out the relationship between the Quality of life (QoL) and cognitive functions and the physical activity in the senior citizens. [1]

Hertzog and colleagues carried out a research in 2009 on physical activity, cognitive activities and social negation. He developed a theory known as cognitive engagement theory about the wellbeing of the senior citizens. He was of the view that the enrich lifestyle which includes physical activities, cognitive functions and social interaction improve the QoL. [2]

Gow et al. emphasize on the identification of the factors that protect or destroy the cognitive abilities in the old age is center to the current objective of this research on cognitive aging. [3]

Anguera et al. carried out a study on the factors which affect the cognitive aging. He was of the view that the decline in the cognitive functions starts at the early adulthood. [4]

Prakash et al. carried out a study and observed that the physical exercise activity not only effect the adulthood but also in advanced age on the cognitive functions in the senior citizens. [5]

Andel et al. carried out a study on the executive functions which are considered to be keys for healthy aging. He was of the view that the cognitive functions can only be maintained through supportive behavior and social interaction. [6]

Cabeza et al. was of the view that every individual is unique in his characteristics in terms of genetic material, biological factors, psychomotor behaviours and social interaction. All these factors play an important role in the development, maintenance and decline of cognitive functions throughout individuals' life. [7]

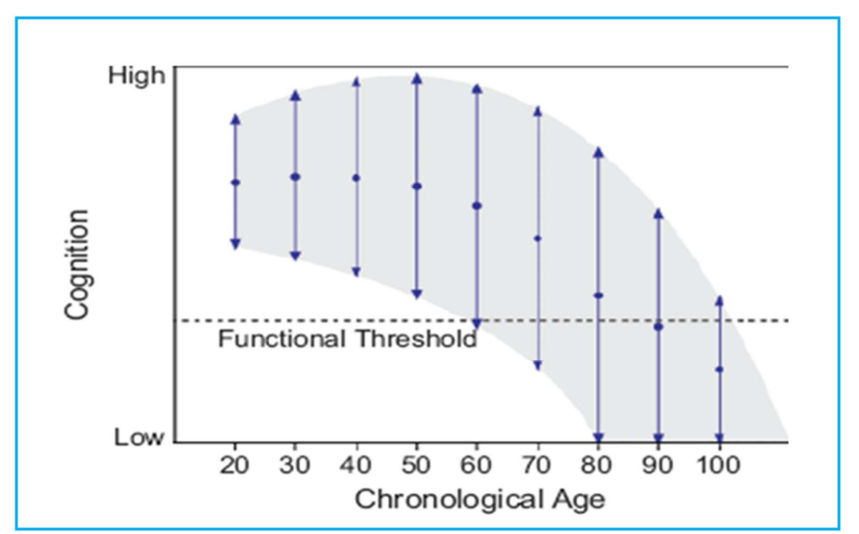

Figure 1. Representation of the potential for cognitive development over the life course for a given individual [2].

Another study was carried out about the invaluable 
potential of the brain due to its plasticity. He found out that the maintenance of the cognitive functions is direct related to the ability of brain plasticity. [2]

The theory of cognitive management has its origin from brain plasticity. The cognitive executive functions are affected by the different external environmental factors from the life of the individual. The theory of cognitive management has four trajectories reflecting the evolution of cognitive abilities throughout life (Figure 2).

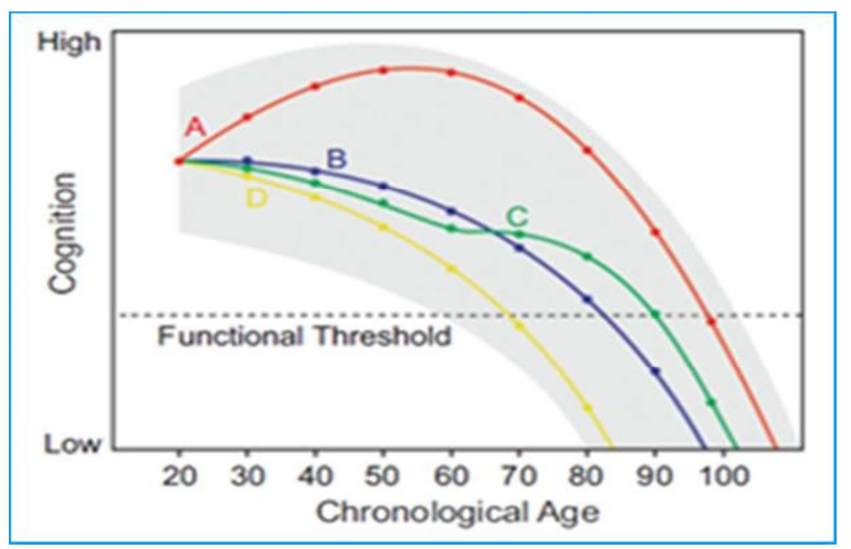

Figure 2. Representation of the potential for cognitive development for a given individual according to four possible developmental trajectories ( $A, B$, C, D) [2].

Curve A shows the border line of the cognitive malleability. It shows that the different behaviours can promote cognitive performance throughout life and even at a very advance age.

Curve B shows the cognitive decline with the increase in age. This curve is dependent on the genetic material, biological properties and its response to the different external factors.

Curve $\mathrm{C}$ shows the concept of cognitive enrichment which is dependent upon high quality of education and practice which promote social interaction and ultimately improve cognitive functions in the advance life.

Curve D shows the bad behavior and negative emotions can lead to rapid cognitive decline in life.

\section{Objective of the Study}

The objectives of the study are:

1. To test and re-test the results of PSCQL-MT questionnaire over a period of 12 months

2. To find out the relationship between the cognitive improvement due to physical exercise activities in the elderly persons.

3. To find out the effect of different variables on QoL in male and female.

\section{Hypothesis}

The following hypothesis will be tested based on the PSCQL-MT questionnaire

H1: Physical exercise activities play an important role in stabilizing or improving the cognitive functions on the basis of gender in the study population.

H2: Physical exercise activities do not play an important role in stabilizing or improving the cognitive functions on the basis of gender in the study population.

\section{Material and Methods}

\section{Study Design:}

Settings: This study has been conducted in District Lahore, Pakistan.

Duration of Study: Twelve Months from the approval of the date of approval by IRB, University of Lahore.

Sampling Technique: The data has been collected from senior citizens, health care givers, Old Homes Administrators, Social Welfare Organizations, Hospitals, Non-Government Organizations, Old People Homes and community at large.

Sample Selection

Inclusion Criteria: All persons who have age of 21 years and above, male or female are included in the study.

Exclusion Criteria: All Persons (Male/Female) having age less than 21 years has excluded from the study.

Study Tools:

$$
\text { Sample size }(n)=(457)
$$

\subsection{Method}

The sample was randomly chosen using purposive sampling method base on 2 Starta. A total number of participants 457 which is included 193 females and 264 males having a mean age of 72.3 and $\mathrm{SD}=12.7$. The senior citizens were choose between ages 60 to 85 years who were having Inclusion Criteria: a) greater than 60 years (b) have an MMSE score greater than 26 [8-9] and (c) score less than 16 on the Beck Depression Scale [10].

Exclusion Criteria were (a) use of medication that may affect cognitive function (e.g., psychotropic drugs) and (b) being colour blind, to the extent that it may interfere with Stroop's test performance.

\subsection{Procedure}

500 index subjects were selected for this study out of which 43 were dropped out. 457 subject index were tested before the start of the study. These senior citizens were tested with the help of Beck scale and the MMSE were administered to verify whether the subject met the inclusion criteria. All volunteers met all inclusion and non-inclusion criteria. All the tests were administered in the same order, so as to promote homogeneity in the conditions under which they were administered among the participants. Subjects first participated in cognitive testing, i.e. The "Matrix reasoning test" followed by the "Stroop's test", then the "Digit Symbol Substitution Test" and finally the "Trail Making Test". Finally, the PSCQL-MT was administered to assess the lifestyle of the participants.

\subsection{Tools and Measures}

QoL has been measured by the Pakistan Senior Citizens 
Quality of Life - Measurement Tool (PSCQL-MT) which is composed of 43 items it includes: (a) cognitive activities (8 items); (b) social activities (9 items); (c) physical activities (9 items); (d) other leisure activities (7 items); and (e) health behaviours $(10$ items $)$. Participants completed the questionnaire by indicating their frequency of participation over the past 12 months, in the activities presented by each item. Responses were given:

5 -point Likert scale, of which 5 indicated daily or neardaily participation

4 participation occurring a few times a week

3 monthly participation

2 participation in an activity that occurred only a few times during the year

1 participation in an activity that had never occurred.

For each QoL dimension measured, the item scores were summed and averaged to obtain a score for each dimension (i.e., cognitive, social, physical, other leisure activities and other health behaviours). An overall QoL score was also calculated by taking the average of all items.

\subsection{Executive Functions}

Executive functions were measured using PSCQL-MT tool. The five neuropsychological tests were used, namely the "Trail Making Test" (TMT) [11], conditions 3 and 4 of the "Stroop Test" [12], the "Digit Symbol Substitution Test" (DSST) [13] and the "Matrix reasoning test" [14].

\subsection{Socio-cultural Level}

In this study, 10 individuals had a socio-cultural level higher than their initial education level (e.g., an individual whose highest degree was a bachelor's degree and whose occupation needs a skill). These 10 subjects (or $9.80 \%$ of the sample) were assigned an additional step, in order to limit cohort effects in this study.

\subsection{Data Processing}

All statistical analyses are performed using SPSS Statistics 19 data analysis software. To begin with, five preliminary analyses were conducted.

1) First, a principal component analysis [15] as well as a calculation of Cronbach's alpha coefficient [16] allowed us to " assess the extent to which the five tests chosen to constitute the composite score measured a single underlying construction. The purpose of this analysis was to verify the validity of the composite score of "executive functions".

2) Secondly, t-tests were used to compare sociodemographic characteristics, participation in the different dimensions of QoL and the cognitive scores of the males and females in the sample. The purpose of these preliminary analyzes is to measure the initial role of the SCL and gender variables in the sample.

3) Third, Pearson correlations were used to make a preliminary observation of the links between the different study variables.
4) In a fourth step, linear regression analyzes made it possible to measure the basic relationship between age and cognition. The objective of this analysis was to verify the validity of our statistical models, since all our analyzes are based on the hypothesis that cognition decreases with age [2], and this forms early adulthood $[4,17,18]$.

5) In a fifth step, linear regression analyzes were used to assess the impact of the SCL and the basic model between age-cognition after the addition of the SCL as a control variable.

Following these preliminary analyzes, the procedure described by Aiken and West was followed in order to carry out moderate regression analysis. All predictor variables were centered (relative to their mean) before being introduced into the analysis. Two multiple regression models were used to test the hypotheses of this study. [19]

H1 test: Effects of lifestyle dimensions on cognitive decline

The objective of model 1 is to measure the moderating role of lifestyle on the age-cognition relationship. (see Figure 3). Model 1 is broken down into different stages of statistical analysis, which will be presented as follows:

a) Analysis of the simple effect of lifestyle on the agecognition relationship, with control of the SCL.

b) Analysis of the interaction effect between age and lifestyle on cognition, with control of the SCL.

c) If the interaction at the end of step $b$ is significant: separate analyzes of the simple effect of age on cognition for different levels of involvement in the activity concerned (high / medium / low).

Finally, a summary table of all these stages will be proposed for each analysis, in order to provide details of the results.

Each of these steps was performed for the overall lifestyle (model 1) and for each of the lifestyle dimensions (cognitive dimension: model 1A, social dimension: model 1B, etc.).

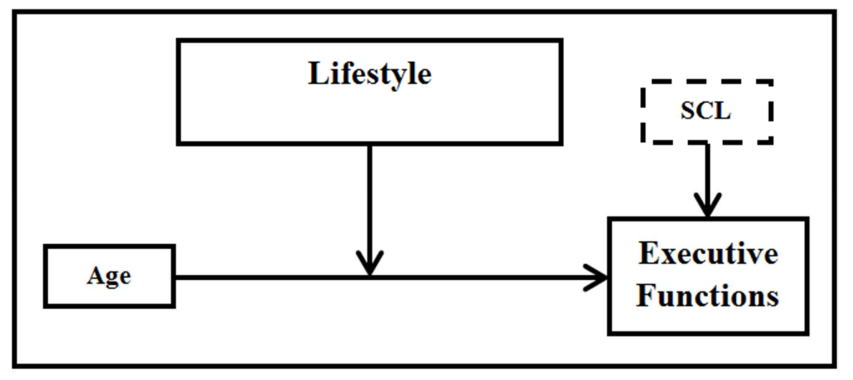

Figure 3. Model 1_Life moderating effect on the age-cognition relationship, with the SCL as a control variable.

H2 test: Moderating role of gender on the impact of lifestyle dimensions on cognitive decline

The objective of model 2 was to measure the additive moderating role of gender in the relationship between lifestyle and age-related cognitive decline (see Figure 4). Model 2 has different stages, which will be presented as follows:

a) Analysis of simple effects: age, gender, lifestyle, with control of the SCL. 
b) Analysis of the effects of dual interactions: age $\mathrm{x}$ gender, age $\mathrm{x}$ lifestyle, gender $\mathrm{x}$ lifestyle, with SCL control.

c) Analysis of the effects of the triple interaction: age $x$ gender $x$ lifestyle, with control of the SCL.

d) If the triple interaction is found significant after step c: separate analyzes of the effect of age $x$ lifestyle interaction on cognition for females vs. males will be calculated.

Finally, a summary table of all these stages has been proposed for each analysis, in order to provide details of the results.

As with model 1, each of these steps was performed for the overall lifestyle (model 2), the cognitive dimension (model 2A), the social dimension (model 2B), etc.

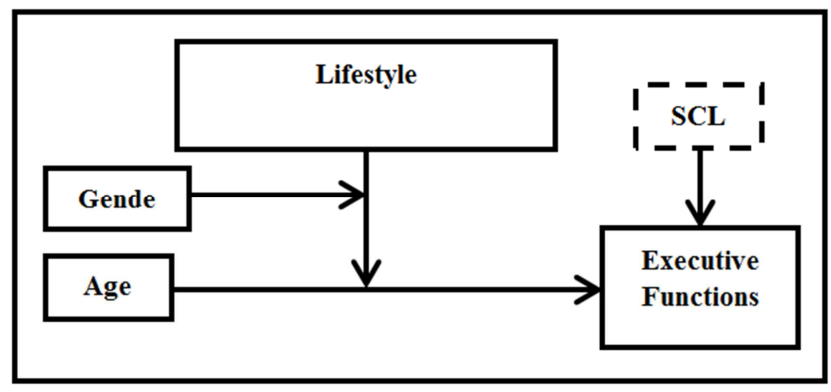

Figure 4. Model 2_Moder effect of gender and lifestyle on the age-cognition relationship, with the SCL as a control variable.

In models 1 and 2, the composite score of executive functions constitutes the criterion variable, age is treated as a continuous variable, lifestyle is considered as a continuous moderating variable in the age-cognition relationship and the SCL is control. For model 2, gender is treated as a dichotomous moderating variable.

\section{Results}

Table 1. Characteristics of the study sample 3.

\begin{tabular}{llll}
\hline Variables & Female N=193 A (SD) & Male N=264 A (SD) & t test \\
\hline Age & $49.67(18.51)$ & $48.93(20.22)$ & 0.19 \\
Years of study & $14.48(3.56)$ & $14.23(3.42)$ & 0.37 \\
Socio-Cultural Level & $3.50(1.33)$ & $3.89(1.28)$ & -1.48 \\
Executive Functions & $0.07(0.89)$ & $0.10(0.69)$ & -1.03 \\
Global Lifestyle & $3.18(0.27)$ & $3.14(0.36)$ & 0.59 \\
Cognitive Lifestyle & $3.10(0.46)$ & $3.18(0.51)$ & -0.78 \\
Social Lifestyle & $2.76(0.44)$ & $2.73(0.63)$ & 0.26 \\
Physical Lifestyle & $3.43(0.61)$ & $3.47(0.81)$ & -0.34 \\
Other leisure activities & $2.91(0.45)$ & $2.85(0.45)$ & 0.66 \\
Other health behaviors & $3.68(0.41)$ & $3.46(0.37)$ & $2.80^{\mathrm{b}}$ \\
Food & $3.28(0.61)$ & $3.13(0.56)$ & 1.32 \\
Tobacco & $4.72(0.69)$ & $4.68(0.61)$ & 0.32 \\
Sleep & $3.78(1.12)$ & $3.88(1.06)$ & -0.45 \\
\hline
\end{tabular}

Note: A=Average, $\mathrm{SD}=$ Standard Deviation. ${ }^{\mathrm{a}} \mathrm{p}<.001 ;{ }^{\mathrm{b}} \mathrm{p}<.01 ;{ }^{\mathrm{c}} \mathrm{p}<.05$.

\subsubsection{Correlations Between Study Variables}

The correlation matrix makes it possible to observe the basic links between the different variables treated within this study (see Table 2). 
Table 2. Correlation matrix for the variables.

\begin{tabular}{|c|c|c|c|c|c|c|c|c|c|c|c|c|}
\hline Variables & 1 & 2 & 3 & 4 & 5 & 6 & 7 & 8 & 9 & 10 & 11 & 12 \\
\hline Age & - & & & & & & & & & & & \\
\hline Years of study & $0.34^{\mathrm{a}}$ & - & & & & & & & & & & \\
\hline Socio-Cultural Level & $0.29^{\mathrm{b}}$ & .14 & - & & & & & & & & & \\
\hline Executive Functions & $0.67^{\mathrm{a}}$ & $.36^{\mathrm{a}}$ & $.52^{\mathrm{a}}$ & - & & & & & & & & \\
\hline Global Lifestyle & $0.38^{\mathrm{a}}$ & .05 & .13 & $.23^{\mathrm{c}}$ & - & & & & & & & \\
\hline Cognitive Lifestyle & 0.17 & 0.04 & $.27^{\mathrm{b}}$ & $.32^{\mathrm{a}}$ & $.60^{\mathrm{a}}$ & - & & & & & & \\
\hline Social Lifestyle & $0.49^{\mathrm{a}}$ & .15 & $.20^{\mathrm{c}}$ & $.39^{\mathrm{a}}$ & $.70^{\mathrm{a}}$ & $.44^{\mathrm{a}}$ & - & & & & & \\
\hline Other leisure activities & $0.20^{\mathrm{c}}$ & 0.01 & .09 & .11 & $.70^{\mathrm{a}}$ & $.42^{\mathrm{a}}$ & $.38^{\mathrm{a}}$ & $.34^{\mathrm{a}}$ & - & & & \\
\hline Health behaviors & $.23^{\mathrm{c}}$ & 0.04 & $0.20^{\mathrm{c}}$ & $0.34^{\mathrm{a}}$ & .21 & 0.12 & 0.16 & .09 & 0.00 & - & & \\
\hline Food & .27 & 0.05 & 0.12 & $0.33^{\mathrm{a}}$ & .16 & 0.16 & 0.17 & .14 & .02 & $.76^{\mathrm{a}}$ & - & \\
\hline Tobacco & $.21^{\mathrm{c}}$ & 0.02 & 0.13 & 0.14 & .01 & 0.07 & 0.13 & 0.05 & .02 & $.34^{\mathrm{a}}$ & 0.09 & - \\
\hline Sleep & .16 & 0.13 & 0.07 & 0.13 & .01 & .03 & 0.09 & .05 & .10 & 0.08 & .06 & $0.25^{\mathrm{c}}$ \\
\hline
\end{tabular}

Note: ${ }^{\mathrm{a}} \mathrm{p}<.001 ;{ }^{\mathrm{b}} \mathrm{p}<.01 ;{ }^{\mathrm{c}} \mathrm{p}<.05$.

\subsubsection{Basic Relationship Between Age and Cognition}

The objective of this second analysis is to ensure the relevance of the basic model between age and cognition in this study. The results show a negative relationship between age and cognition $(\beta=0.667, p<.001)$, resulting in a significant decline in cognition as people get older (see Figure 5). This model, composed solely of age as a predictor, explains $44.5 \%$ of the variance in cognitive functions ( $F$ $(1.100)=80.12, \mathrm{p}<.001)$.

In addition, the correlation $(\mathrm{r}=0.67, \mathrm{p}<.001)$ and the associated linear trend curve show that the decline begins at the start of adulthood (see Figure 6).

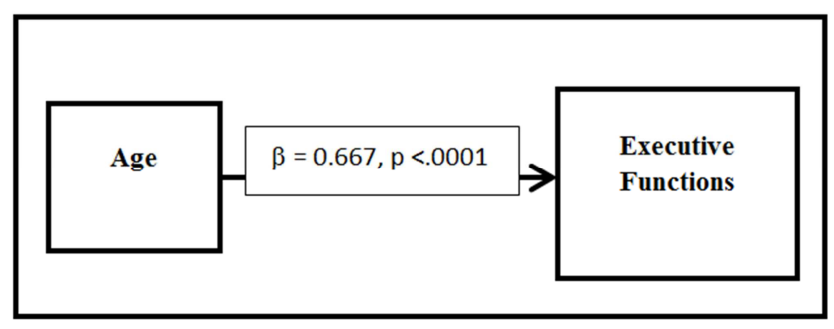

Figure 5. Base of the statistical model representing the basic relationship between age (continuous predictor) and cognition (composite score).

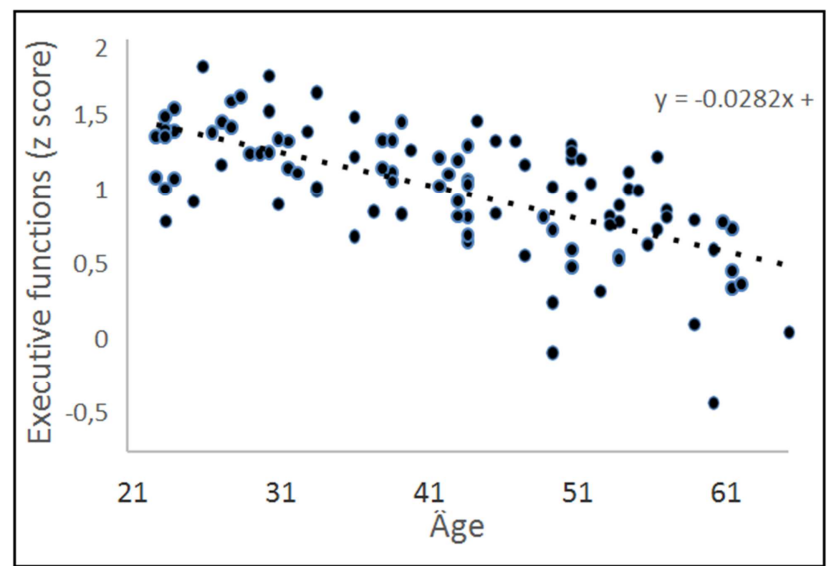

Figure 6. Basic relationship between age and cognition.

\subsection{Impact of the Socio-Cultural Level}

A regression analysis shows the significance of the positive link between the SCL and cognitive performance $(\beta=.523, p<.001)$. The coefficient of determination is 0.27 , which means the regression modal is explaining dependent variable by $27 \%$ approximately. The variable SCL alone seems to explain more than a quarter of the variance in cognitive functions $\left(\mathrm{R}^{2}=27.4 \%\right)$.

As a reminder, our research is based on the negative relationship between age and cognition $(\beta=0.667, \mathrm{p}<.001)$. The SCL variable playing an important role on cognitive performance, we want, as a precaution, to check that our basic model rest on the addition of SCL. The significance of the negative relationship between age and cognition is maintained despite the addition of the variable SCL to the basic model $(\mathrm{F}(2,99)=63.85, \mathrm{p}<.001)$ and this model explains $56.33 \%$ of the variance.

\subsubsection{Analysis of Models 1: Moderating Effect of Physical Exercise on Age-related Cognitive Decline}

The purpose of this study to test the following hypothesis:

H1: Physical exercise activities play an important role in stabilizing or improving the cognitive functions in the study population.

This study has been carried out for a period of one year in order to test the hypothesis by using PSCQL-MT questionnaire and tool. Before the start of a study, the participants of the study were clearly defined for physical exercises to be carried out. The cognitive functions of the ADL and IADL were clearly defined to the participants. The methodology and the usage of data were also been explained them to improve their voluntarily participation in the study. They were trained for 10 days before the start of the study. Weekly three hours physical training was given to all the participants in the study. The number of participants in the study were 457 which included 264 males and 193 females having an age range of 60 to 85 years, Mean=72.3, $\mathrm{SD}=12.7$.

The result of the physical exercise activities were measured at the interval of $3,6,9$ and 12 months to check the effectiveness of physical exercise activities impact on the cognitive executive function and ADL and IADL. After three months of physical exercise activities, there was no significant improvement in the cognitive executive functions in males and females. The additional interaction of physical exercise in 
cognitive improvement does not show a significant increase in the variance of cognation $\left(\Delta \mathrm{R}^{2}=.004, \mathrm{p}=.514\right)$.

Table 3. Model 1 of normalized $\beta$ values from multiple regression analyzes for the lifestyle dimension.

\begin{tabular}{llll}
\hline \multirow{2}{*}{ Variables } & \multicolumn{2}{l}{ Lifestyle } & \\
\cline { 2 - 4 } & Step 1 & Step 2 & Step 3 \\
\hline Age & $0.577 \mathrm{a}$ & $0.598 \mathrm{a}$ & $0.604 \mathrm{a}$ \\
SCL & $.374 \mathrm{a}$ & $.374 \mathrm{a}$ & $.363 \mathrm{a}$ \\
Lifestyle & & 0.050 & 0.047 \\
Lifestyle x Age & & & .066 \\
R2 & $.576 \mathrm{a}$ & $.579 \mathrm{a}$ & $.583 \mathrm{a}$ \\
$\Delta \mathrm{R} 2$ & $.576 \mathrm{a}$ & .002 & .004 \\
\hline
\end{tabular}

Note: SCL=Socio-Cultural Level. ${ }^{a} \mathrm{p}<.001 ;{ }^{b} \mathrm{p}<.01 ;{ }^{\mathrm{c}} \mathrm{p}<.05$.

\subsubsection{Analysis of the Impact of QoL on Cognitive Executive Functions}

The relationship between the QoL and the cognitive executive functions has been studied. It has been found out that the QoL have a significant increase in the cognitive executive functions.

Table 4. Model 1 of normalized $\beta$ values from multiple regression analyzes for the "cognitive" executive functions dimension.

\begin{tabular}{llll}
\hline \multirow{2}{*}{ Variables } & \multicolumn{3}{c}{ Cognitive executive functions } \\
\cline { 2 - 4 } & Step 1 & Step 2 & Step 3 \\
\hline Age & $0.577^{\mathrm{a}}$ & $0.561^{\mathrm{a}}$ & $0.563^{\mathrm{a}}$ \\
$\mathrm{SCL}$ & $.374^{\mathrm{a}}$ & $.341^{\mathrm{a}}$ & $.335^{\mathrm{a}}$ \\
Cognitive Executive Functions & & $.137^{\mathrm{c}}$ & .125 \\
Cognitive Executive Functions x Age & & & .052 \\
$\mathrm{R}^{2}$ & $.576^{\mathrm{a}}$ & $.594^{\mathrm{a}}$ & $.596^{\mathrm{a}}$ \\
$\Delta \mathrm{R}^{2}$ & $.576^{\mathrm{a}}$ & $.017^{\mathrm{c}}$ & .002 \\
\hline
\end{tabular}

Note: SCL=Socio-Cultural Level. ${ }^{\mathrm{a}} \mathrm{p}<.001 ;{ }^{\mathrm{b}} \mathrm{p}<.01 ;{ }^{\mathrm{c}} \mathrm{p}<.05$.

\subsubsection{Analysis of the Impact of Social Interaction on the Cognitive Aging}

It has been observed during the study that the social interaction play a signification role in improving the cognitive aging in the elderly persons. The value of variance of cognition show an insignificant increase in the cognitive level due to social interaction $\left(\Delta \mathrm{R}^{2}=.002, \mathrm{p}=.505\right)$.

Table 5. Model 1 of normalized $\beta$ values from multiple regression analyzes for the "social" interaction dimension.

\begin{tabular}{llll}
\hline \multirow{2}{*}{ Variables } & \multicolumn{3}{l}{ Social Interaction } \\
\cline { 2 - 4 } & Step 1 & Step 2 & Step 3 \\
\hline Age & $0.577^{\mathrm{a}}$ & $0.554^{\mathrm{a}}$ & $0.565^{\mathrm{a}}$ \\
SCL & $.374^{\mathrm{a}}$ & $.370^{\mathrm{a}}$ & $.350^{\mathrm{a}}$ \\
Social Interaction & & .050 & .043 \\
Social Interaction x Age & & & .077 \\
$\mathrm{R}^{2}$ & $.576^{\mathrm{a}}$ & $.578^{\mathrm{a}}$ & $.584^{\mathrm{a}}$ \\
$\Delta \mathrm{R}^{2}$ & $.576^{\mathrm{a}}$ & $.002^{\mathrm{c}}$ & .006 \\
\hline
\end{tabular}

Note: SCL=Socio-Cultural Level. ${ }^{a} \mathrm{p}<.001 ;{ }^{b} \mathrm{p}<.01 ;{ }^{\mathrm{c}} \mathrm{p}<.05$.

\subsubsection{Analysis of the Impact of Physical Exercise Activities on the Cognitive Aging}

Effect of physical exercise was measured at interval of 3,6 , 9 and 12 months both in males and females in the study population. The short term physical exercise does not show any improvement which can be confirmed by the variance of cognition $\left(\Delta \mathrm{R}^{2}<.001, \mathrm{p}=.729\right)$.

Table 6. Model 1 of normalized $\beta$ values from multiple regression analyzes for the "physical exercise activity" dimension.

\begin{tabular}{llll}
\hline \multirow{2}{*}{ Variables } & \multicolumn{3}{l}{ Physical Exercise Activity } \\
\cline { 2 - 4 } & Step 1 & Step 2 & Step 3 \\
\hline Age & $0.577^{\mathrm{a}}$ & $0.619^{\mathrm{a}}$ & $0.623^{\mathrm{a}}$ \\
SCL & $.374^{\mathrm{a}}$ & $.367^{\mathrm{a}}$ & $.364^{\mathrm{a}}$ \\
PEA & & 0.108 & 0.110 \\
PEA x Age & & & .023 \\
$\mathrm{R}^{2}$ & $.576^{\mathrm{a}}$ & $.587^{\mathrm{a}}$ & $.587^{\mathrm{a}}$ \\
$\Delta \mathrm{R}^{2}$ & $.576^{\mathrm{a}}$ & $.010^{\mathrm{c}}$ & .001 \\
\hline
\end{tabular}

Note: PEA=Physical Exercise Activity. $\mathrm{SCL}=$ Socio-Cultural Level. ${ }^{\mathrm{a}} \mathrm{p}<.001$; ${ }^{\mathrm{b}} \mathrm{p}<.01 ;{ }^{\mathrm{c}} \mathrm{p}<.05$.

\subsubsection{Analysis of the Impact of "Other Leisure Activities" on Cognitive Aging}

Our study showed that leisure activities have positive impact on cognitive functions in the elderly persons. The interaction leads to an insignificant increase in the explained variance of cognition $\left(\Delta \mathrm{R}^{2}=.004, \mathrm{p}=.346\right)$.

Table 7. Model 1 of normalized $\beta$ values from multiple regression analyzes for the dimension "other leisure activities".

\begin{tabular}{llll}
\hline \multirow{2}{*}{ Variables } & \multicolumn{3}{l}{ Other Leisure Activities } \\
\cline { 2 - 4 } & Step 1 & Step 2 & Step 3 \\
\hline Age & $0.577^{\mathrm{a}}$ & $0.587^{\mathrm{a}}$ & $0.584^{\mathrm{a}}$ \\
$\mathrm{SCL}$ & $.374^{\mathrm{a}}$ & $.374^{\mathrm{a}}$ & $.374^{\mathrm{a}}$ \\
Other Leisure Activities & & 0.043 & 0.048 \\
Other Leisure Activities x Age & & & .063 \\
$\mathrm{R}^{2}$ & $.576^{\mathrm{a}}$ & $.578^{\mathrm{a}}$ & $.582^{\mathrm{a}}$ \\
$\Delta \mathrm{R}^{2}$ & $.576^{\mathrm{a}}$ & .002 & .004 \\
\hline
\end{tabular}

Note: SCL=Socio-Cultural Level. ${ }^{\mathrm{a}} \mathrm{p}<.001 ;{ }^{\mathrm{b}} \mathrm{p}<.01 ;{ }^{\mathrm{c}} \mathrm{p}<.05$.

\subsubsection{Analysis of the Impact of the Health Behaviors on the Cognitive Functions in the Elderly Persons}

The relationship was studied between the health behavior and cognitive functions in the senior citizens. A significant increase in the explained variance of cognation was found in the elderly persons $\left(\Delta \mathrm{R}^{2}=.002, \mathrm{p}=.024\right)$.

Table 8. Model 1 of normalized $\beta$ values from multiple regression analyzes for the dimension "health behaviors".

\begin{tabular}{llll}
\hline \multirow{2}{*}{ Variables } & \multicolumn{3}{l}{ Health Behaviour } \\
\cline { 2 - 4 } & Step 1 & Step 2 & Step 3 \\
\hline Age & $0.577^{\mathrm{a}}$ & $0.561^{\mathrm{a}}$ & $0.571^{\mathrm{a}}$ \\
SCL & $.374^{\mathrm{a}}$ & $.350^{\mathrm{a}}$ & $.350^{\mathrm{a}}$ \\
Health Behaviour & & $0.150^{\mathrm{c}}$ & $0.155^{\mathrm{c}}$ \\
Health Behaviour x Age & & & 0.046 \\
$\mathrm{R}^{2}$ & $.576^{\mathrm{a}}$ & $.578^{\mathrm{a}}$ & $.582^{\mathrm{a}}$ \\
$\Delta \mathrm{R}^{2}$ & $.576^{\mathrm{a}}$ & $.002^{\mathrm{c}}$ & .004 \\
\hline
\end{tabular}

Note: SCL=Socio-Cultural Level. ${ }^{a} \mathrm{p}<.001 ;{ }^{b} \mathrm{p}<.01 ;{ }^{\mathrm{c}} \mathrm{p}<.05$.

\subsubsection{Impact of the "Food" on the Cognitive Functions in the Elderly Persons}

The study of relationship between the diet and cognitive functions needs a long duration study. In the short term, there is no signification in the explained variance of cognition. However, after the study has been prolonged for more than one year and measurement was made. It was found that the 
significant improvement due to health diet in the cognitive functions was observed in the elderly persons. $\left(\Delta \mathrm{R}^{2}=.025\right.$, $\mathrm{p}=.016),(\beta=0.159, \mathrm{p}=.016)$.

Table 9. Model 1 of normalized $\beta$ values of the multiple regression analyzes for the "food" sub-dimension.

\begin{tabular}{llll}
\hline \multirow{2}{*}{ Variables } & \multicolumn{2}{l}{ Food Sub-Dimensions } \\
\cline { 2 - 4 } & Step 1 & Step 2 & Step 3 \\
\hline Age & $0.577^{\mathrm{a}}$ & $0.552^{\mathrm{a}}$ & $0.577^{\mathrm{a}}$ \\
SCL & $.374^{\mathrm{a}}$ & $.369^{\mathrm{a}}$ & $.362^{\mathrm{a}}$ \\
Food & & $0.159^{\mathrm{c}}$ & $0.167^{\mathrm{c}}$ \\
Food x Age & & & 0.061 \\
$\mathrm{R}^{2}$ & $.576^{\mathrm{a}}$ & $.601^{\mathrm{a}}$ & $.604^{\mathrm{a}}$ \\
$\Delta \mathrm{R}^{2}$ & $.576^{\mathrm{a}}$ & $.025^{\mathrm{c}}$ & .003 \\
\hline
\end{tabular}

Note: SCL=Socio-Cultural Level. ${ }^{\mathrm{a}} \mathrm{p}<.001 ;{ }^{\mathrm{b}} \mathrm{p}<.01 ;{ }^{\mathrm{c}} \mathrm{p}<.05$.

\subsubsection{Impact of the Smoking on the Cognitive Functions in the Elderly}

The impact of smoking on the cognition function does not show any insignificant change in the short term in the explained variance of cognition $\left(\Delta \mathrm{R}^{2}=.007, \mathrm{p}=.194\right)$.

Table 10. Model 1 of normalized $\beta$ values from multiple regression analyzes for the "Smoking" sub-dimension.

\begin{tabular}{llll}
\hline \multirow{2}{*}{ Variables } & \multicolumn{3}{l}{ Smoking Sub-Dimensions } \\
\cline { 2 - 4 } & Step 1 & Step 2 & Step 3 \\
\hline Age & $0.577^{\mathrm{a}}$ & $0.580^{\mathrm{a}}$ & $0.569^{\mathrm{a}}$ \\
SCL & $.374^{\mathrm{a}}$ & $.376^{\mathrm{a}}$ & $.384^{\mathrm{a}}$ \\
Smoking & & $0.022^{\mathrm{c}}$ & 0.024 \\
Smoking x Age & & & 0.098 \\
$\mathrm{R}^{2}$ & $.576^{\mathrm{a}}$ & $.577^{\mathrm{a}}$ & $.584^{\mathrm{a}}$ \\
$\Delta \mathrm{R}^{2}$ & $.576^{\mathrm{a}}$ & .000 & .007 \\
\hline
\end{tabular}

Note: $\mathrm{SCL}=$ Socio-Cultural Level. ${ }^{\mathrm{a}} \mathrm{p}<.001 ;{ }^{\mathrm{b}} \mathrm{p}<.01 ;{ }^{\mathrm{c}} \mathrm{p}<.05$.

\subsubsection{Impact of the "Sleep" on the Cognitive Functions in the Elderly}

The relationship between the sleep and the cognitive functions in the elderly persons were studied. It was found out that there was no insignificant change in the short duration study in the explained variance of cognation $\left(\Delta \mathrm{R}^{2}=.002, \mathrm{p}=.521\right)$.

Table 11. Model 1 of normalized $\beta$ values from multiple regression analyzes for the "sleep" sub-dimension.

\begin{tabular}{llll}
\hline \multirow{2}{*}{ Variables } & \multicolumn{3}{l}{ Sleep Sub-Dimensions } \\
\cline { 2 - 4 } & Step 1 & Step 2 & Step 3 \\
\hline Age & $0.577^{\mathrm{a}}$ & $0.584^{\mathrm{a}}$ & $0.594^{\mathrm{a}}$ \\
SCL & $.374^{\mathrm{a}}$ & $.363^{\mathrm{a}}$ & $.356^{\mathrm{a}}$ \\
Sleep & & 0.057 & 0.060 \\
Sleep x Age & & & .052 \\
$\mathrm{R}^{2}$ & $.576^{\mathrm{a}}$ & $.580^{\mathrm{a}}$ & $.582^{\mathrm{a}}$ \\
$\Delta \mathrm{R}^{2}$ & $.576^{\mathrm{a}}$ & .003 & .003 \\
\hline
\end{tabular}

Note: SCL=Socio-Cultural Level. ${ }^{a} \mathrm{p}<.001 ;{ }^{b} \mathrm{p}<.01 ;{ }^{\mathrm{c}} \mathrm{p}<.05$.

\subsection{Analysis of Role of Gender}

\subsubsection{Analysis of Role of Gender on the Cognitive Functions in Male and Female}

The result of our study showed that recent physical exercise activity does not improve cognitive functions in male and female. This may be due to delayed response to the different stimulation in the elderly persons. The three month physical activity in male and female did not show any insignificant increase in the explained variance of cognation $\left(\Delta \mathrm{R}^{2}=.004, \mathrm{p}=.300\right)$

Table 12. Model 2 of normalized $\beta$ values from multiple regression analyzes for the "cognitive" dimension.

\begin{tabular}{lllll}
\hline \multirow{2}{*}{ Variables } & QoL & & & \\
\cline { 2 - 5 } & Step 1 & Step 2 & Step 3 & Step 4 \\
\hline Age & $0.577^{\mathrm{a}}$ & $0.562^{\mathrm{a}}$ & $0.763^{\mathrm{a}}$ & $0.762^{\mathrm{a}}$ \\
SCL & $.374^{\mathrm{a}}$ & $.339^{\mathrm{a}}$ & $.332^{\mathrm{a}}$ & $.331^{\mathrm{a}}$ \\
Gender & & .015 & .017 & .006 \\
Cognitive & & $.137^{\mathrm{c}}$ & $.587^{\mathrm{b}}$ & $.517^{\mathrm{c}}$ \\
Cognitive x Age & & & .229 & .230 \\
Cognitive x Gender & & & .033 & .262 \\
Age x Gender & & & $0.488^{\mathrm{c}}$ & $0.426^{\mathrm{c}}$ \\
Cognitive x Age x Gender & & & & 0.234 \\
& & & & $.629^{\mathrm{a}}$ \\
$\mathrm{R}^{2}$ & $.576^{\mathrm{a}}$ & $.594^{\mathrm{a}}$ & $.633^{\mathrm{a}}$ \\
$\Delta \mathrm{R}^{2}$ & $.576^{\mathrm{a}}$ & .018 & $.035^{\mathrm{c}}$ & .004 \\
\hline
\end{tabular}

Note: $\mathrm{QoL}=\mathrm{QoL}, \mathrm{SCL}=$ Socio-Cultural Level. ${ }^{\mathrm{a}} \mathrm{p}<.001 ;{ }^{\mathrm{b}} \mathrm{p}<.01 ;{ }^{\mathrm{c}} \mathrm{p}<.05$.

\subsubsection{Analysis of the Role of Gender, QoL and Its Impact on Cognitive Functions}

The result of our study showed double and triple interaction between the different variables which did not show any significant increase in the explained variance of the cognation in the short term $\left(\Delta \mathrm{R}^{2}=.002, \mathrm{p}=.761\right)$.

However, the analysis of impact of triple interaction of variable in the long term showed a significant increase in the explained variance of cognation $\left(\Delta \mathrm{R}^{2}=.032, \mathrm{p}=.005\right)(\beta=-.636$, $\mathrm{p}=.005)$.

Table 13. Model 2 of normalized $\beta$ values from multiple regression analyzes for the "social interaction" dimension.

\begin{tabular}{lllll}
\hline \multirow{2}{*}{ Variables } & QoL & & & \\
\cline { 2 - 5 } & Step 1 & Step 2 & Step 3 & Step 4 \\
\hline Age & $0.577^{\mathrm{a}}$ & $0.554^{\mathrm{a}}$ & $0.733^{\mathrm{a}}$ & $0.802^{\mathrm{a}}$ \\
$\mathrm{SCL}$ & $.374^{\mathrm{a}}$ & $.365^{\mathrm{a}}$ & $.307^{\mathrm{a}}$ & $.278^{\mathrm{a}}$ \\
Gender & & .022 & .039 & 0.047 \\
Social Interaction & & .052 & .471 & .439 \\
Social Interaction x Age & & & .100 & $.705^{\mathrm{b}}$ \\
Social Interaction x Gender & & & -.433 & 0.390 \\
Age x Gender & & & -.190 & .245 \\
Social Interaction x Age x Gender & & & & $-.636^{\mathrm{b}}$ \\
& & & & \\
$\mathrm{R}^{2}$ & $.576^{\mathrm{a}}$ & $.579^{\mathrm{a}}$ & $.610^{\mathrm{a}}$ & $.642^{\mathrm{a}}$ \\
$\Delta \mathrm{R}^{2}$ & $.576^{\mathrm{a}}$ & .002 & .032 & $.032^{\mathrm{b}}$ \\
\hline
\end{tabular}

Note: $\mathrm{QoL}=\mathrm{QoL}, \mathrm{SCL}=$ Socio-Cultural Level. ${ }^{\mathrm{a}} \mathrm{p}<.001 ;{ }^{\mathrm{b}} \mathrm{p}<.01 ;{ }^{\mathrm{c}} \mathrm{p}<.05$.

\subsubsection{Analysis of the Role of Gender Between Physical Exercise Activity and Cognitive Functions in the Elderly}

Our study showed that there was no significant change in the explained variance of cognition with double or triple interaction in the short term $\left(\Delta \mathrm{R}^{2}=.015, \mathrm{p}=.309\right)$. 
Table 14. Model 2 of normalized $\beta$ values from multiple regressions analyzes for the "physical exercise Activity" dimension.

\begin{tabular}{|c|c|c|c|c|}
\hline \multirow{2}{*}{ Variables } & \multicolumn{4}{|l|}{ QoL } \\
\hline & Step 1 & Step 2 & Step 3 & Step 4 \\
\hline Age & $-.577^{\mathrm{a}}$ & $-.620^{\mathrm{a}}$ & $-.893^{\mathrm{a}}$ & $-.960^{\mathrm{a}}$ \\
\hline SCL & $.374^{\mathrm{a}}$ & $.362^{\mathrm{a}}$ & $.344^{\mathrm{a}}$ & $.338^{\mathrm{a}}$ \\
\hline Gender & & .024 & .032 & -.009 \\
\hline PEA & & -.109 & .078 & .070 \\
\hline PEA x Age & & & .279 & .335 \\
\hline PEA x Gender & & & .043 & .407 \\
\hline Age x Gender & & & -.193 & -.178 \\
\hline PEA x Age $x$ Gender & & & & -.384 \\
\hline $\mathrm{R}^{2}$ & $.576^{\mathrm{a}}$ & $.579^{\mathrm{a}}$ & $.602^{\mathrm{a}}$ & $.614^{\mathrm{a}}$ \\
\hline$\Delta \mathrm{R}^{2}$ & $.576^{\mathrm{a}}$ & .011 & .015 & .012 \\
\hline
\end{tabular}

Note: $\mathrm{QoL}=\mathrm{QoL}, \mathrm{SCL}=$ Socio-Cultural Level. ${ }^{\mathrm{a}} \mathrm{p}<.001 ;{ }^{\mathrm{b}} \mathrm{p}<.01 ;{ }^{\mathrm{c}} \mathrm{p}<.05$.

\subsubsection{Analysis of the Role of Gender Between QoL and Leisure Activities to the Cognitive Functions in the Elderly}

The result of our study showed there was significant in the explained variance of cognation in three double interaction $\left(\Delta \mathrm{R}^{2}=.034, \mathrm{p}=.048\right)$.

However, the result of the effect of triple interaction of gender, QoL and physical exercise activities showed a significant increase in the long term in the explained variance of cognition $\left(\Delta \mathrm{R}^{2}=.018, \mathrm{p}=.038\right)(\beta=-.421, \mathrm{p}=.038)$.

Table 15. Model 2 of normalized $\beta$ values from multiple regression analyzes for the dimension "other leisure activities".

\begin{tabular}{lllll}
\hline \multirow{2}{*}{ Variables } & QoL & & & \\
\cline { 2 - 5 } & Step 1 & Step 2 & Step 3 & Step 4 \\
\hline Age & $-.577^{\mathrm{a}}$ & $-.587^{\mathrm{a}}$ & $-.892^{\mathrm{a}}$ & $-.877^{\mathrm{a}}$ \\
SCL & $.374^{\mathrm{a}}$ & $.371^{\mathrm{a}}$ & $.341^{\mathrm{a}}$ & $.349^{\mathrm{a}}$ \\
Gender & & .016 & .018 & -.018 \\
other Leisure Activities & & -.041 & .308 & .265 \\
other Leisure Activities x Age & & .325 & .285 \\
other Leisure Activities x Gender & & & .089 & $.482^{\mathrm{c}}$ \\
Age x Gender & & & -.381 & -.331 \\
other Leisure Activities x Age x Gender & & & & $-.421^{\mathrm{c}}$ \\
$\mathrm{R}^{2}$ & $.576^{\mathrm{a}}$ & $.578^{\mathrm{a}}$ & $.612^{\mathrm{a}}$ & $.630^{\mathrm{a}}$ \\
$\Delta \mathrm{R}^{2}$ & $.576^{\mathrm{a}}$ & .002 & $.034^{\mathrm{c}}$ & $.018^{\mathrm{c}}$ \\
\hline
\end{tabular}

Note: $\mathrm{QoL}=\mathrm{QoL}, \mathrm{SCL}=$ Socio-Cultural Level. ${ }^{\mathrm{a}} \mathrm{p}<.001 ;{ }^{\mathrm{b}} \mathrm{p}<.01 ;{ }^{\mathrm{c}} \mathrm{p}<.05$.

\subsubsection{Analysis of the Role of Gender Between QoL and Other Health Behaviors to the Cognitive Functions in the Elderly Persons}

The result of our study showed that there was insignificant increase in the explained variance of cognition. The significant increase was due to health behaviours $\left(\Delta \mathrm{R}^{2}=.022\right.$, $\mathrm{p}=.078)(\beta=0.154, \mathrm{p}=.025)$.

The analysis of three double interaction to the model does not show any insignificant increase in the short term in the explained variance of cognitive functions. $\left(\Delta \mathrm{R}^{2}=.014\right.$, $\mathrm{p}=.344)$.

The analysis of the results of triple interaction showed an insignificant increase in the long term in the explained variance of cognation $\left(\Delta \mathrm{R}^{2}=.002, \mathrm{p}=.500\right)$.
Table 16. Model 2 of normalized $\beta$ values of multiple regression analyzes for the dimension "health behaviors".

\begin{tabular}{lcccc}
\hline \multirow{2}{*}{ Variables } & QoL & & & \\
\cline { 2 - 5 } & Step 1 & Step 2 & Step 3 & Step 4 \\
\hline Age & $-.577^{\mathrm{a}}$ & $-.560^{\mathrm{a}}$ & $-.897^{\mathrm{a}}$ & $-.877^{\mathrm{a}}$ \\
SCL & $.374^{\mathrm{a}}$ & $.353^{\mathrm{a}}$ & $.341^{\mathrm{a}}$ & $.333^{\mathrm{a}}$ \\
Gender & & -.017 & -.010 & -.002 \\
Health Behaviour & & $-.154^{\mathrm{c}}$ & -.201 & -.188 \\
Health Behaviour x Age & & & .351 & .311 \\
Health Behaviour x Gender & & & -.009 & .134 \\
Age x Gender & & & .047 & .037 \\
Health Behaviour x Age x Gender & & & & -.158 \\
$\mathrm{R}^{2}$ & $.576^{\mathrm{a}}$ & $.598^{\mathrm{a}}$ & $.612^{\mathrm{a}}$ & $.614^{\mathrm{a}}$ \\
$\Delta \mathrm{R}^{2}$ & $.576^{\mathrm{a}}$ & .022 & .014 & .002 \\
\hline
\end{tabular}

Note: $\mathrm{QoL}=\mathrm{QoL}, \mathrm{SCL}=$ Socio-Cultural Level. ${ }^{\mathrm{a}} \mathrm{p}<.001 ;{ }^{\mathrm{b}} \mathrm{p}<.01 ;{ }^{\mathrm{c}} \mathrm{p}<.05$.

\subsubsection{Impact of Gender and Food to the Cognitive Functions in the Elderly Persons}

The results of our study showed a significant increase due to healthy diet in the long term $\left(\Delta \mathrm{R}^{2}=.025, \mathrm{p}=.055\right)$.

The result of analysis of three double interaction does not show a significant increase in the in the short term in the explained variance of cognition $\left(\Delta \mathrm{R}^{2}=.015, \mathrm{p}=.302\right)$.

The result of the analysis of triple interaction showed significant increase in the long term in the explained variance of cognition $\left(\Delta \mathrm{R}^{2}=.001, \mathrm{p}=.689\right)$

Table 17. Model 2 of normalized $\beta$ values of the multiple regression analyzes for the "food" sub-dimension.

\begin{tabular}{lllll}
\hline \multirow{2}{*}{ Variables } & QoL & & & \\
\cline { 2 - 5 } & Step 1 & Step 2 & Step 3 & Step 4 \\
\hline Age & $-.577^{\mathrm{a}}$ & $-.552^{\mathrm{a}}$ & $-.830^{\mathrm{a}}$ & $-.857^{\mathrm{a}}$ \\
$\mathrm{SCL}$ & $.374^{\mathrm{a}}$ & $.368^{\mathrm{a}}$ & $.363^{\mathrm{a}}$ & $.366^{\mathrm{a}}$ \\
Gender & & $-.159^{\mathrm{c}}$ & -.319 & -.331 \\
Food & & .003 & .021 & .018 \\
Food x Age & & & .273 & .310 \\
Food x Gender & & & -.049 & -.131 \\
Age x Gender & & & .171 & .182 \\
Food x Age x Gender & & & & -.091 \\
$\mathrm{R}^{2}$ & $.576^{\mathrm{a}}$ & $.601^{\mathrm{a}}$ & $.616^{\mathrm{a}}$ & $.617^{\mathrm{a}}$ \\
$\Delta \mathrm{R}^{2}$ & $.576^{\mathrm{a}}$ & .025 & .015 & .001 \\
\hline
\end{tabular}

Note: $\mathrm{QoL}=\mathrm{QoL}, \mathrm{SCL}=$ Socio-Cultural Level. ${ }^{\mathrm{a}} \mathrm{p}<.001 ;{ }^{\mathrm{b}} \mathrm{p}<.01 ;{ }^{\mathrm{c}} \mathrm{p}<.05$.

\subsubsection{Impact of Gender and Smoking to the Age Related Cognition in Elderly Persons}

The result of smoking does not show any change in the short term in the explained variance of cognition $\left(\Delta R^{2}=.001\right.$, $\mathrm{p}=.910)$.

The result of the analysis of three double interaction did not show any change in the explained variance of cognition $\left(\Delta \mathrm{R}^{2}=.022, \mathrm{p}=.162\right)$.

The result of the analysis of triple also show no significant change in the long term in the explained variance of cognition $\left(\Delta \mathrm{R}^{2}=.004, \mathrm{p}=.331\right)$. 
Table 18. Model 2 of normalized $\beta$ values from multiple regression analyzes for the "Smoking" sub-dimension.

\begin{tabular}{lllll}
\hline \multirow{2}{*}{ Variables } & QoL & & & \\
\cline { 2 - 5 } & Step 1 & Step 2 & Step 3 & Step 4 \\
\hline Age & $-.577^{\mathrm{a}}$ & $-.581^{\mathrm{a}}$ & $-.855^{\mathrm{a}}$ & $-.884^{\mathrm{a}}$ \\
SCL & $.374^{\mathrm{a}}$ & $.372^{\mathrm{a}}$ & $.352^{\mathrm{a}}$ & $.363^{\mathrm{a}}$ \\
Gender & & $.019^{\mathrm{c}}$ & .035 & .040 \\
Smoking & & .022 & -.224 & -.100 \\
Smoking x Age & & & .291 & .313 \\
Smoking x Gender & & & -.087 & .150 \\
Age x Gender & & & .215 & .106 \\
Smoking x Age x Gender & & & & -.236 \\
$\mathrm{R}^{2}$ & $.576^{\mathrm{a}}$ & $.577^{\mathrm{a}}$ & $.600^{\mathrm{a}}$ & $.604^{\mathrm{a}}$ \\
$\Delta \mathrm{R}^{2}$ & $.576^{\mathrm{a}}$ & .001 & .022 & .004 \\
\hline
\end{tabular}

Note: $\mathrm{QoL}=\mathrm{QoL}, \mathrm{SCL}=$ Socio-Cultural Level. ${ }^{\mathrm{a}} \mathrm{p}<.001 ;{ }^{\mathrm{b}} \mathrm{p}<.01 ;{ }^{\mathrm{c}} \mathrm{p}<.05$.

\subsubsection{Impact of Gender and Sleep to the Age Related Cognitive Functions in the Elderly Persons}

The result of our study showed that variable sleep did not show any significant change in the explained variance of cognition $\left(\Delta \mathrm{R}^{2}=.001, \mathrm{p}=.925\right)$.

The result of the analysis of three double interaction did not show any significant change in the explained variance of cognation $\left(\Delta \mathrm{R}^{2}=.016, \mathrm{p}=.292\right)$.

The result of the analysis of triple interaction did not show any significant change in the explained variance of cognation $\left(\Delta \mathrm{R}^{2}=.000, \mathrm{p}=.855\right)$.

Table 19. Model 2 of normalized $\beta$ values of the multiple regression analyzes for the "sleep" sub-dimension.

\begin{tabular}{lllll}
\hline \multirow{2}{*}{ Variables } & QoL & & & \\
\cline { 2 - 5 } & Step 1 & Step 2 & Step 3 & Step 4 \\
\hline Age & $-.577^{\mathrm{a}}$ & $-.578^{\mathrm{a}}$ & $-.915^{\mathrm{a}}$ & $-.918^{\mathrm{a}}$ \\
SCL & $.374^{\mathrm{a}}$ & $.370^{\mathrm{a}}$ & $.364^{\mathrm{a}}$ & $.363^{\mathrm{a}}$ \\
Gender & & $.021^{\mathrm{c}}$ & .028 & .028 \\
Sleep & & -.018 & -.045 & -.044 \\
Sleep x Age & & & .391 & .384 \\
Sleep x Gender & & & .068 & .059 \\
Age x Gender & & & .020 & .018 \\
Sleep x Age x Gender & & & & -.010 \\
$\mathrm{R}^{2}$ & $.576^{\mathrm{a}}$ & $.577^{\mathrm{a}}$ & $.593^{\mathrm{a}}$ & $.593^{\mathrm{a}}$ \\
$\Delta \mathrm{R}^{2}$ & $.576^{\mathrm{a}}$ & .001 & .016 & .000 \\
\hline
\end{tabular}

Note: $\mathrm{QoL}=\mathrm{QoL}, \mathrm{SCL}=$ Socio-Cultural Level. ${ }^{\mathrm{a}} \mathrm{p}<.001 ;{ }^{\mathrm{b}} \mathrm{p}<.01 ;{ }^{\mathrm{c}} \mathrm{p}<.05$.

\section{Discussion}

This study has been carried out to identify the factors that can preserve or prevent the age related cognitive decline in the senior citizens. The scope of this study was to find out the moderating factors which can preserve cognitive executive functions in the senior citizens. The first hypothesis was stated "Physical exercise activities play an important role in stabilizing or improving the cognitive functions in both the genders in the study population." The second hypothesis describes "The physical exercise play an important role in improving the cognitive executive functions in women as compare to males."

This study has been carried out on the two hypotheses described above which was further on different variables which can improve or preserve the cognitive executive functions in the elderly population.

Grande et al. carried out a study to find out the benefits of enriched lifestyle. He found out that the long term use of enriched facilities can preserve the cognitive functions in the elderly population. [20]

Kelly et al. carried out a study to find out the cognitive preservations and its relationship to the QoL. He was of the opinion that the improved QoL help elderly in maintaining their cognitive functions. [21]

The role of gender in maintaining the cognitive functions in elderly is a matter of debate in the literature.

Freeman et al. carried out a study about the benefit of social interaction on the cognitive aging. He was of the view that the social interaction in the women preserved the cognitive function and physical activities in the females. He was further of the view that the preservation of the cognitive functions is due to the social ties of the women in the family is more stronger as compare to man due to physical and mental activities in the family. [22]

Audiffren was of the view that the physical activity and the cognitive functions are interrelated with one and another. He was of the view that the social interaction can further improve the cognitive functions in the elderly persons. He carried out an experimental study to find out these results. [1]

Di Marco et al. carried out a study to find out the factors which can preserve the physical and the cognitive wellbeing in the elderly persons. He was of the view that the social interactions improve the mood in the elderly person which leads to preservation of cognitive functions in the senior citizens.[23]

Zeidan et al. carried out a study to find out the role of leisure activities in preserving cognitive executive functions in the elderly persons. He was of the view that the ADL and IADL can only be done; if the persons are involved in the healthy leisure activities in their daily life. [24]

Our study is more related on the concept of physical exercise activities and its impact on the cognitive executive functions in the elderly. The PSCQL-MT questionnaire contains all the dimensions which are necessary to find out the relationship of physical activities and cognitive functions in terms of ADL and IADL. The PSCQL-MT questionnaire and the modified questionnaires are very closed in terms of their dimensions.

Beason-Held et al. carried out a study to see the relationship between the physical exercise and its impact on the brain. He was of the view that the short term physical activity does not produce significant results. However, if the physical exercise activity are carried out for more than one year produces a signification improvement in the cognitive functions in the elderly. [25]

Arfanakis et al. carried out a study to check the impact of different variables on the cognitive functions in the elderly. He was of the opinion that the cognitive functions can be improved over a long period of time due to different variables i.e. physical activity and health behavior. [26]

Díaz-Morales \& Escribano carried out a study to find a 
relationship between the sleep and cognitive functions. He was of the view that the sleep does not improve the cognitive functions in the elderly persons in the short term. [27]

Kesse-Guyot et al. carried out the study to find out the impact of balanced diet and the cognitive functions preservations. He was of the view that the long term use of balanced diet can improve the cognitive functions preservation in the elderly. [28]

Cunnane et al. carried out a study on the fatty foods which preserve the cognitive functions and prevent the persons from dementia. Carbohydrates are the main source of energy which also prevents a person from developing cognitive decline. [29]

The result of all these studies are in line with our present study showing that the physical exercise activity in the long term can preserve cognitive functions in the elderly persons. There are also different co-factors like social interaction, balanced diet and leisure activities which can further improve cognitive executive functions in the elderly persons to improve the ADL and IADL.

\section{Conclusion}

It has been concluded from the study that our hypothesis H1: Physical exercise activities play an important role in stabilizing or improving the cognitive functions on the basis of gender in the study population. The hypothesis was tested on the basis of PSCQL-MT questionnaire which have been tested for validity construct and reliability having a Cronbach's alpha value of 0.9 . The moderating factors like cognitive activities, social activities, physical activities, leisure activities and health behavior. Play an important role in performing activities of daily living and instrumental activities of daily living in the senior citizens.

\section{References}

[1] Audiffren, M. (2011). Positive effects of chronic physical exercise on the cognitive functions of seniors: assessment and outlook. Neuropsychology review, 3 (4), 207-225. doi: 10.3917 / rne.034.0207.

[2] Hertzog, C., Kramer, A. F., Wilson, R. S., \& Lindenberger, U. (2009). Enrichment effects on adult cognitive development: can the functional capacity of older adults be preserved and enhanced? Psychological science in the public interest, 9 (1), 1-65. doi: $10.1111 / \mathrm{j} .1539-6053.2009 .01034 . x$.

[3] Gow, A. J., Pattie, A., \& Deary, I. J. (2017). Lifecourse Activity Participation From Early, Mid, and Later Adulthood as Determinants of Cognitive Aging: The Lothian Birth Cohort 1921. The Journals of Gerontology Series B: Psychological Sciences and Social Sciences, 72 (1), 25-37. doi: 10.1093/geronb/gbw124.

[4] Anguera, J. A., Boccanfuso, J., Rintoul, J. L., Al-Hashimi, O., Faraji, F., Janowich, J.,... \& Gazzaley, A. (2013). Video game training improves cognitive control in the elderly. Nature, 501 (7465), 97-101. doi: 10.1038 / nature12486.

[5] Prakash, R. S., Voss, M. W., Erickson, K. I., \& Kramer, A. F.
(2015). Physical activity and cognitive vitality. Annual review of psychology, 66, 769-797. doi: 10.1146/annurev-psych010814- 015249.

[6] Andel, R., Silverstein, M., \& Kareholt, I. (2014). The role of midlife occupational complexity and leisure activity in latelife cognition. The Journals of Gerontology Series B: Psychological Sciences and Social Sciences, 70 (2), 314-321. doi: 10.1093/geronb/gbu110.

[7] Cabeza, R., Nyberg, L., \& Park, D. (2016). Cognitive neuroscience of aging: Linking cognitive and cerebral aging. Oxford University Press. doi: 10.1093/acprof:oso/9780199372935.001.00 01.

[8] Folstein, M. F., Folstein, S. E., \& McHugh, P. R. (1975). "Mini-mental state": a practical method for grading the cognitive state of patients for the clinician. Journal of psychiatric research, 12 (3), 189-198.

[9] Hebert, L. E., Scherr, P. A., Beckett, L. A., Funkenstein, H. H., Albert, M. S., Chown, M. J., \& Evans, A. (1992). Relation of smoking and alcohol consumption to incident Alzheimer's disease. American journal of epidemiology, 135 (4), 347-355.

[10] Beck, A. T., Steer, R. A., \& Carbin, M. G. (1988). Psychometric properties of the Beck Depression Inventory: Twenty-five years of evaluation. Clinical psychology review, 8 (1), 77-100. doi: 10.1016/0272-7358(88) 90050-5.

[11] Corrigan, J. D., \& Hinkeldey, N. S. (1987). Relationships between parts A and B of the Trail Making Test. Journal of clinical psychology, 43 (4), 402-409.

[12] Stroop, J. R. (1935). Studies of interference in serial verbal reactions. Journal of experimental psychology, 18 (6), 643.

[13] Wechsler, D. (1997). WAIS-III: Administration and scoring manual: Wechsler adult intelligence scale. Psychological Corporation.

[14] Wechsler, D. (1999). Wechsler Abbreviated Scale of Intelligence. San Antonio, TX: The Psychological Corporation.

[15] Wilson, R. S., Scherr, P. A., Schneider, J. A., Tang, Y., \& Bennett, D. A. (2007). Relation of cognitive activity to risk of developing Alzheimer disease. Neurology, 69 (20), 19111920. doi: 10.1212/01.wnl.0000271087.67782.cb.

[16] Boucard, G. K., Albinet, C. T., Bugaiska, A., Bouquet, C. A., Clarys, D., \& Audiffren, M. (2012). Impact of physical activity on executive functions in aging: a selective effect on inhibition among old adults. Journal of Sport and Exercise Psychology, 34 (6), 808-827. doi: 10.1123/jsep. 34.6.808.

[17] Li, S.-C., Lindenberger, U., Hommel, B., Aschersleben, G., Prinz, W., \& Baltes, P. B. (2004). Transformations in the couplings among intellectual abilities and constituent cognitive processes across the life span. Psychological Science, 15 (3), 155-163. doi: 10.1111/j.09567976.2004.01503003.x.

[18] Salthouse, T. A. (2009). When does age-related cognitive decline begin? Neurobiology of aging, 30 (4), 507-514. doi: 10.1016/j.neurobiolaging.2008.09.023.

[19] Aiken, L. S., \& West, S. G. (1991). Multiple regression: Testing and interpreting interactions. Newbury Park, London, Sage. 
[20] Grande, G., Vanacore, N., Maggiore, L., Cucumo, V., Ghiretti, R., Galimberti, D., \& Clerici, F. (2014). Physical activity reduces the risk of dementia in mild cognitive impairment subjects: a cohort study. Journal of Alzheimer's Disease, 39 (4), 833-839. doi: 10.3233/JAD- 131808.

[21] Kelly, M. E., Loughrey, D., Lawlor, B. A., Robertson, I. H., Walsh, C., \& Brennan, S. (2014). The impact of exercise on the cognitive functioning of healthy older adults: A systematic review and meta-analysis. Ageing Research Reviews, 16, 1231. doi: 10.1016/j.arr.2014.05.002.

[22] Freeman, S., Spirgiene, L., Martin-Khan, M., \& Hirdes, J. P. (2016). Relationship between restraint use, engagement in social activity, and decline in cognitive status among residents newly admitted to long-term care facilities. Geriatrics \& gerontology international, 17 (2), 246- 255. doi: 10.1111/ggi.12707.

[23] Di Marco, L. Y., Marzo, A., Muñoz-Ruiz, M., Ikram, M. A., Kivipelto, M., Ruefenacht, D.,... \& Frangi, A. F. (2014). Modifiable lifestyle factors in dementia: a systematic review of longitudinal observational cohort studies. Journal of Alzheimer's Disease, 42 (1), 119-135. 10.3233/JAD- 132225.

[24] Zeidan, F., Johnson, S. K., Diamond, B. J., David, Z., \& Goolkasian, P. (2010). Mindfulness meditation improves cognition: Evidence of brief mental training. Consciousness and cognition, 19 (2), 597-605. doi: 10.1016/j.concog.2010.03.014.
[25] Beason-Held, L. L., Moghekar, A., Zonderman, A. B., Kraut, M. A., \& Resnick, S. M. (2007). Longitudinal changes in cerebral blood flow in the older hypertensive brain. Stroke, 38 (6), 1766-1773. doi: 10.1161/STROKEAHA.106.477109.

[26] Arfanakis, K., Wilson, R. S., Barth, C. M., Capuano, A. W., Vasireddi, A., Zhang, S.,... \& Bennett, D. A. (2015). Cognitive activity, cognitive function, and brain diffusion characteristics in old age. Brain imaging and behavior, 10 (2), 455-463. doi: 10.1007/s11682-015-9405-5.

[27] Díaz-Morales, J. F., \& Escribano, C. (2015). Social jetlag, academic achievement and cognitive performance: understanding gender/sex differences. Chronobiology $\begin{array}{llll}\text { international, } & 32 & (6), & 822-831 .\end{array}$ $10.3109 / 07420528.2015 .1041599$.

[28] Kesse-Guyot, E., Andreeva, V. A., Lassale, C., Hercberg, S., \& Galan, P. (2014). Clustering of midlife lifestyle behaviors and subsequent cognitive function: a longitudinal study. American journal of public health, 104 (11), 170-177. doi: 10.2105/AJPH.2014.302121.

[29] Cunnane, S. C., Plourde, M., Pifferi, F., Bégin, M., Féart, C., \& Barberger-Gateau, P. (2009). Fish, docosahexaenoic acid and Alzheimer's disease. Progress in lipid research, 48 (5), 239-256. doi: 10.1016/j.plipres.2009.04.001. 